\title{
Analysis on Regional Economy Development View and Model
}

\author{
Weiwei Zhu \\ Zhengzhou University of Science and Technology, Zhengzhou,450002, China
}

\author{
Keywords: Regional economy, Development, Model
}

\begin{abstract}
Regional economic development is the top priority of China's political construction and economic construction, involving social stability and national security issues. Therefore we can say regional economic development is the only way to implement the scientific concept of development and build a socialist harmonious society. Only accelerate the improvement ideas, establish a correct concept of regional economic development, positively apply state preferential policies, and play regional advantages, in order to truly achieve sustainable development of regional economy.

The so-called regional economy mainly refers to the economic complex economic activities carried out within a certain range, due to the inherent associated natural conditions, economic region, to achieve national cultural traditions, social development, trade and other economic flows together constitute the commonwealth, is as a whole in general of the national economy within the scope of a particular region. Regional economy as an important force to support economic development in all regions, plays vital role for achieving balanced regional development, shorten the development gap between the metro, it has become an important way to China's current economic and social development.
\end{abstract}

\section{Status of regional economic development}

\section{Regional industrial competitiveness to be improved}

In the current situation of regional economic development, although the dominant material basis of industry, the market more solid foundation. But as the pace of global economic integration is speeding up, plus further competition in the market, the existing industrial development model is clearly not suited to the new situation. Mainly for the following aspects: (1) irrational industrial structure; (2) industry concentration is low; (3) independent R \& D capability is not strong. Thus, due to various factors, constraints enhance the competitiveness of leading industries, not necessarily conducive to the overall development of the regional economy. According intensive economic factors, China's development of regional economy leading industries most labor-intensive and capital-intensive, the lack of high technological content, good industry value chain, with independent intellectual property brand products. So, if you want to truly achieve regional economic development, we must increase innovation, optimize the industrial structure, improve the core competitiveness of leading industries.

\section{SMEs have limited competitiveness}

Although SMEs play an important role in China's economic development, but it is undeniable that there are some flaws in terms of technology, capital, etc., plus the development of SMEs in their lack of power, often by means of external forces, for technical achievement through technology transfer. But in the technology transfer process, often encounter some difficulties or risks; restrict the healthy development of SMEs. For SMEs, due to the development of a limited size, and therefore products and services are often difficult to meet the diverse needs of customers, even if the products have been successful due to insufficient capital investment, weak level of technology and other reasons, the product quality is difficult to guarantee, but not conducive to the development new product. 


\section{Regional integration and development of industrial and technical resources}

Currently, the pace of regional economic interaction and integration is within a range of slow, urgent need to accelerate the integration speed. In development of the regional economy, the industrial structural convergence phenomenon still exists in all regions in the development of industrial policy, select leading industries, with similar tendencies. This will lead to excessive competition between regions, resulting in misallocation of resources, and waste.

\section{Regional economic development model}

\section{Promote economic integration development}

Regional economic integration emphasizes the region of the body in different spaces, in order to obtain many benefits of production, trade and consumption, the formation of market integration process, including product market of production factors, and other aspects of economic policy unification content. To further reduce the gap between the regional economy and achieve coordinated development goals, we must implement the process of regional economic integration, regional cooperation to build a sound system:

Complete organizational system

On the basis of the relevant stakeholders have a common will, based on the establishment of a permanent mechanism that particular area. While taking their own establishment, the relevant state departments involved, local government involvement integration model. The main functions of the agency are: the establishment of the economic zone differences depending on the mode, regular reporting, reflecting the relevant circumstances; organizing regional framework for cooperation between the implementation of conceptual planning, good pre-assessment of major socio-economic activities, coordination of regional the non-legal conflict of interests, safeguard the interests of regional investors, etc. ${ }^{[4]}$. It should be noted that the choice of what kind of form development, regional agencies work sequence are not attributable to the official government agencies, but taking into account the internal organization of management cannot do without government. Provision is also made daily needs of all parties involved in assessments or donations from the community approach.

\section{Build contract system}

Based on past experience and lessons learned, it is to strength regional cooperation in a targeted manner and delivers consultation among parties to honor their commitments. For example, related to economic development across the Region, the need for the government to strengthen supervision and improve the efficiency of investment activity, the promotion of trade flows and personnel exchanges, or reach an agreement between the Government, through friendly consultations, although these agreements cannot be legal form or notarized form security, but in the actual development process, it was decided in the government's credit status, it has credibility performed ${ }^{[5]}$. Once the appearance of conflict of interests between regions, the government should protect the interests of the performing party and take some punitive measures to improve not performing party's attention.

\section{Continuously broaden financing channels}

Government to play the macro-control means, to encourage commercial banks to support projects in emerging industries, for the approval of relevant government departments, the record industry projects, should increase credit support, while subsidized loans will be partially financed by the government merit. Actively improve and build new industries regional venture fund to encourage investment consistent with the national industrial policy, in early-stage start-ups, bigger and stronger enterprises. Priority selection criteria consistent with emerging industry corporate bonds and corporate debt issuance support the development of science and technology enterprises. While playing macro-management and organizational guiding role of government in the capital market, increase policy tilt, play to regional advantages in resources, appropriate tax relief, train more sources of revenue ${ }^{[6]}$. While strengthening the high-tech enterprises, especially SMEs consulting, talent 
introduction, technology transfer, financial management and financing, investment and other service-oriented, improve the development of regional capital markets, learn from advanced foreign "offshore market" development experience, build in line with China's national conditions characteristic of financial markets through the center of the city, optimize the financing environment.

\section{Realize reasonable regional division of work}

Reasonable regional division of work is to achieve coordinated development of regional economy a top priority. Follow the actual situation of industrial development, speed up the transfer or the upgrading of industrial structure, through the integration of the internal vertical division method of traditional industries; accelerate regional optimal allocation of industrial resources. In the regional division process should focus on the following issues:

a). Lay in expanding the size of the market under the premise of the continuous deepening division of labor, to further expand the size of the market, while focusing on the integration of a causal relationship between cycling and positive feedback;

b). Adhere weaknesses, focusing on the development of regional advantages, reasonable choice leading industries. Currently, the area of specialization is to achieve regional division at the heart of the region should be based on actual natural conditions, development status, economic conditions, as a starting point, choose the appropriate leading industries, promote their development, particularly prone to high-tech products, the traditional advantages industry, modern service industry, aims to enhance the competitiveness of the region as a whole, could be considered a vertical and horizontal division of labor division combination, try to avoid simplification ${ }^{[7]}$. For each area of competitive industries, should seek steadily improve regional competitiveness, gain more space for economic development.

c). Continue to reduce the division of costs and enhance the division of labor benefits. On the one hand, the regional division of labor cost issues, from the government level, both microeconomic considerations. Consider the cost of government level include friction costs of different levels of government, the cost of government regulation and supporting the industrial layout and the overall development of the regional economy generated cost; the cost of micro-economic body, should take into account the costs arising due to the location of choice issues, such as transport cost of the product, the cost of marketing, taxation costs. Only cost two aspects balanced and coordinated development, in order to form a real rationalization of regional division of labor ${ }^{[8]}$. On the other hand, benefit regional division is also related to the different aspects, it may give the body region have different interests, how to carefully handle the contradiction between the interests of the regional problem, is inseparable from the interests of coordination and compensation mechanisms, and ultimately to enhance regional overall interests as the goal. In conclusion, on the basis of a reasonable division of labor, in order to realize regional economic collaboration and development.

\section{Accelerate technological innovation}

Economic prosperity and progress, sustainable development cannot be separated. And technological innovation as the only way to develop the regional economy may be primarily to strengthen efforts in the following aspects:

Innovate regional technology development environment

For technological innovation, the influence of the environment cannot be ignored. Government is to promote technological innovation and the premise that the creation of favorable environment for development. In fact, the environment is the dynamic concept of technological innovation, with the development of society and the actual situation is different. But the role of governments in the region to build the innovation environment cannot be ignored, the government should take active measures to provide support and protection for the innovation.

Encourage enterprise independent innovation in an all-round way

For enterprise development, the innovation is different from mere imitation or the introduction of technology, but requires enterprises to continuously improve the core technology, a breakthrough technology originally internal change dependent on external technology, by virtue of their own 
strength, strengthen research and development, its core to grasp the initiative in innovation, access to core technology.

\section{Cultivate innovation talents}

Optimize the allocation of resources; it is the driving force for regional economic development. In the era of knowledge economy, the importance of human resources has become increasingly prominent. Human resources are more similar to the distribution of production in kind in the general sense, he stressed the effectiveness of management. As an enterprise management personnel, should fully understand the characteristics of technology innovators to meet the needs of multi-level, fully mobilize the manpower advantage, enhance innovation capability and core competitiveness. But in view of the current state of economic development, technological innovation and personnel or general lack of knowledge structure is irrational, as a constraint to regional economic development is a major problem. Therefore, accelerating regional technology innovation, improve personnel training awareness, coupled with a series of incentives to continue to increase the proportion of regional economic development in the art, to provide intellectual support for accelerating innovation.

Increase investment in innovation

In the majority of our businesses, especially small and medium enterprises generally insufficient funds, the impact of the development of innovative capabilities. On the one hand, due to the poor economic efficiency, there are limited sources of capital accumulation; on the other hand, the lack of technological innovation financing supplies. Therefore, we should constantly improve the technology innovation fund, especially for the production, development of high-tech products business for financial tilt; to encourage scientific and technological enterprises allocated some funds for investment in industrial or technology development.

\section{Push cooperation between local universities and economic development}

Colleges and universities as a force behind the development of the regional economy, they should strengthen cooperation and economic development, in order to achieve win-win situation. Mainly to do the following:

a). The two sides work together to promote the development, in the form of cooperation to achieve win-win situation, set the same goals;

b). Build a platform for cooperation and innovation, as a university development support and cooperation on the basis of the local economy; to our current point of view and way of technological innovation, the future development and regional economic innovation universities, we will focus on the level of the current platform quality. Therefore, the university should pay attention on regional science and technology and cultural development, organization of multidisciplinary force, together with the local economic base to build decision-making, can undertake more major research projects, provide technical support and rear-area support; identify key points of bilateral cooperation. As colleges and universities to enhance the awareness of the service economy, take the initiative to market themselves, promote themselves, better play to their strengths and advantages, but only around the actual situation of regional economic development and solve major issues in economic and social, quickly locate their own advantages and Economy rendezvous demand, efforts to promote bilateral cooperation, improve the effectiveness of cooperation.

\section{Conclusions}

As seen above, in brand new development opportunities and circumstances, each region should promote regional economic development to an important level, and a large pattern of coordinated development of consideration and planning, raise awareness of opportunities to develop awareness, establish the role of consciousness, looking from challenges the opportunity to develop the opportunities advantages, to achieve regional economic integration and development, enhance the overall core competitiveness. 


\section{References}

[1] Li Jianlin. China regional economic development strategy based on development view evolution and spatial pattern adjustment. Economic geography,2007(6)

[2] Zhang Yang. Strive to develop financial services, promote regional economic development. People Forum, 2011(24) 